\title{
PENGARUH PEMODELAN MASSA PADA ANALISIS DINAMIK STRUKTUR
}

\author{
Bambang Purnijanto ${ }^{1^{*}}$, Trias Widorini ${ }^{2}$, Anik Kustirini ${ }^{3}$ \\ 1,2,3 JurusanTeknik Sipil FT. Universitas Semarang (USM) \\ Jl. Soekarno Hatta, Tlogosari , Semarang, Jateng, Indonesia \\ *e-mail :aabams@usm.ac.id
}

\begin{abstract}
Indonesia is a country prone to natural disasters as Indonesia the industry is located at an active three-plate (plate) meeting namely the Indian Ocean, Eurasian and Pacific plates. As a result of the earthquake can cause many casualties of property and lives. Most of the causes of fatalities from the earthquake are building debris. Damage to buildings is generally caused by design factors and improper implementation. The research carried out has the aim to compare the structural responses that occur due to earthquake loads in buildings with asymmetrical configurations in the form of $T$ and $L$ in a centralized mass model against a scattered mass model. Based on the results of structural analysis for $T$ and L-shaped building plans with different mass modeling, it can be concluded that the centralized mass model produces a larger deviation than the scattered mass model so that it will produce safer conditions.

Keywords: mass modeling; deviation; building; dynamic analysis.
\end{abstract}

\begin{abstract}
ABSTRAK
Indonesia adalah negara yang rawan terjadi bencana alam gempa bumi sebab lokasi Indonesia di pertemuan tiga lempeng (pelat) tektonik yang aktif yaitu lempeng Samudra Hindia, Eurasia dan Pasifik. Akibat dari adanya gempa bumi tersebut dapat menyebabkan banyak korban harta benda dan jiwa. Kebanyakan penyebab korban jiwa akibat gempa bumi ini adalah tertimpa reruntuhan bangunan. Kerusakan bangunan tersebut pada umumnya disebabkan oleh faktor desain dan pelaksanaan yang kurang tepat. Penelitian yang dilakukan mempunyai tujuan untuk membandingkan respons struktur yang terjadi akibat beban gempa pada gedung dengan konfigurasi yang tidak simetris berbentuk $T$ dan $L$ pada model massa terpusat terhadap model massa tersebar. Berdasarkan hasil analisis struktur untuk denah bangunan berbentuk $T$ dan $L$ dengan pemodelan massa yang berbeda maka dapat ditarik kesimpulan bahwa model massa terpusat menghasilkan simpangan yang lebih besar dibandingkan model massa tersebar sehingga akan menghasilkan kondisi yang lebih aman.

Kata kunci : pemodelan massa; simpangan; gedung; analisis dinamik.
\end{abstract}

\section{PENDAHULUAN}

Pada analisis dinamik beban gempa yang bekerja pada bangunan dipengaruhi oleh massa struktur. Gedung bertingkat yang tidak simetris atau tidak beraturan penempatan massa struktur menjadi tersebar tidak beraturan letaknya, sehingga efek beban gempa terhadap struktur tidak dapat dapat diketahui dengan mudah.

Untuk menyelesaikan permasalahan tersebut maka pada umumnya diperlukan penyederhanaan dalam analisis, dimana struktur yang sebenarnya dibuat ideal yaitu dilakukan pemodelan dalam hal ini pemodelan massa struktur. Pemodelan diperlukan supaya penyelesaian masalah tersebut bisa dilakukan secara mudah dengan prinsip matematika.

Proses perancangan (analisis dan desain) struktur merupakan salah satu langkah kerja bidang rekayasa struktur yang banyak melibatkan alat bantu. Sebelum melakukan analisis struktur adalah membuat model struktur sebagai tiruan perilaku fisik struktur yang sebenarnya supaya bisa dianalisis melalui pendekatan numerik pada waktu perencanaan. Pemodelan struktur tidak hanya berhenti di penyiapan data saja, tetapi pemodelan 
seharusnya disesuaikan dengan dengan problem yang akan dianalisisa (Dewobroto, 2004).

Pemodelan struktur menjadi hal yang penting agar problem yang kompleks dapat ditransfer menjadi problem yang sederhana dan secara matematik mudah diselesaikan . Penyederhanaan atau asumsi yang diambil pada model dibuat sedemikian rupa sehingga diperoleh tingkat ketelitian yang cukup memadai tanpa ada kesalahan yang berarti (Widodo, 2001).

Komarudin (2017) meneliti respon struktur gedung dengan bentuk $T$ dan $L$ terhadap spektrum respons apabila kedua bentuk tersebut mempunyai inertia sama. Dari hasil penelitiannya didapatkan bahwa waktu getar dan momen maksimum bentuk L lebih kecil dari bentuk T. Sedangkan perpindahan, rasio antar tingkat dan torsi bentuk T lebih kecil dari bentuk $\mathrm{L}$.

Pranata (2006) mengevaluasi kinerja gedung beton bertulang yang dimodelkan sebagai massa terpusat dengan analisis beban dorong dan analisis inelastik dinamik riwayat waktu. Evaluasi kinerja ini dapat memberikan informasi sejauh mana gempa akan mempengaruhi struktur bangunan gedung pasca leleh.

\section{METODE PENELITIAN}

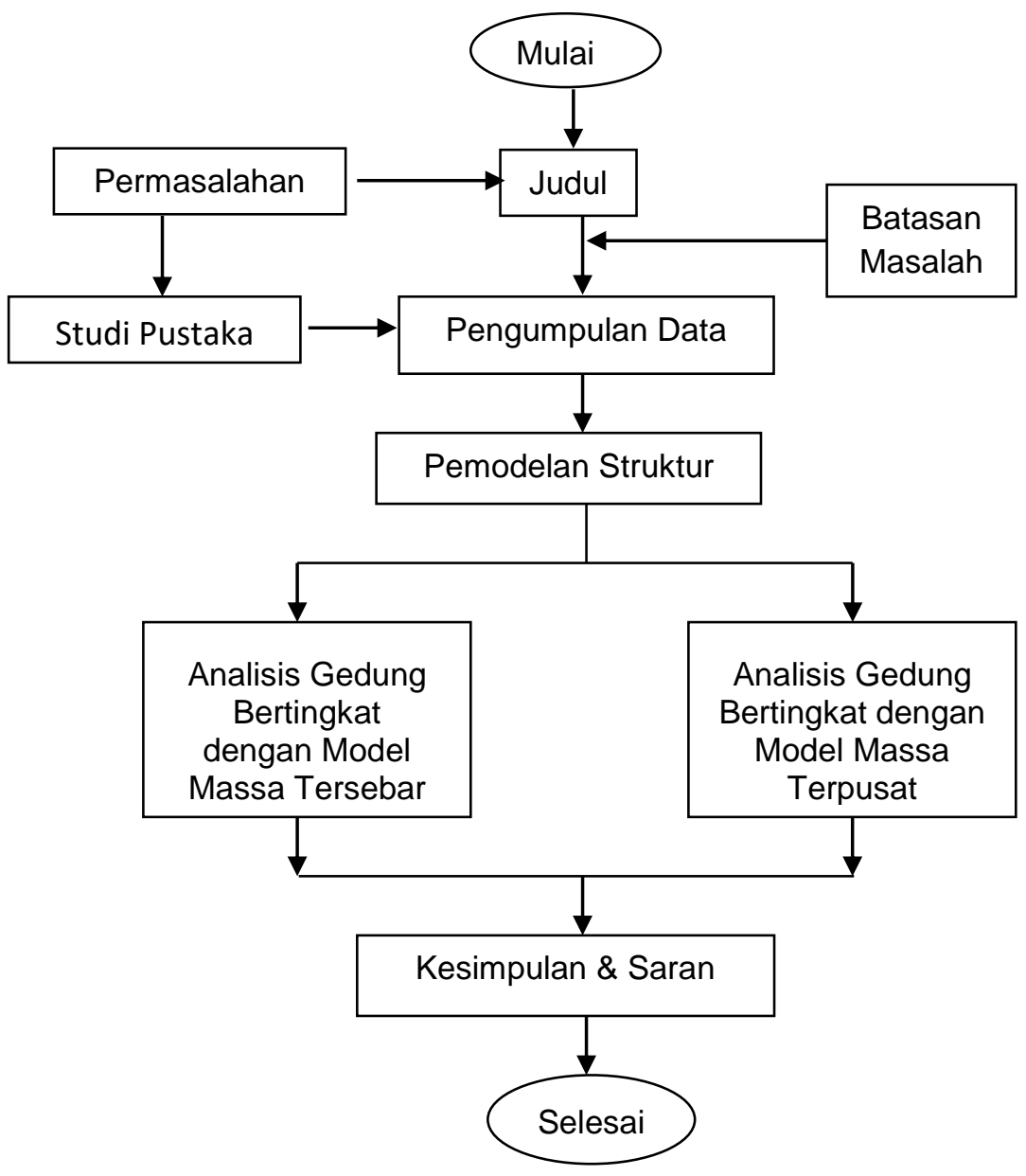

Gambar 1. Diagram Alir Penelitian 
Langkah-langkah penelitian sebagai berikut :

1. Menentukan model bangunan bertingkat tidak simetris.

2. Menentukan data-data pendukung dan beban-beban yang akan digunakan.

3. Membuat pemodelan struktur dengan massa tersebar dan massa terpusat.

4. Melakukan analisis menggunakan program bantu SAP 2000.

5. Pembahasan hasil analisis struktur.

6. Membuat kesimpulan dari hasil analisis.

Data-data yang akan digunakan untuk mendesain model struktur adalah sebagai berikut :

- Pemanfaatan bangunan gedung : Kantor

- Jumlah tingkat $: 5$

- Tinggi tiap tingkat $\quad: 4,0 \mathrm{~m}$

- Jarak antar kolom : :5,0 m

- Bahan

: Beton bertulang

- Mutu bahan

- Beton

- Baja tulangan

: $25 \mathrm{MPa}$

: $400 \mathrm{MPa}$

- Berat jenis beton

- Dimensi

- Kolom (lantai 1-3)

: $2400 \mathrm{~kg} / \mathrm{m}^{3}$

- Kolom (lantai 4-5)

$: 50 / 50$

- balok

$40 / 40$

- Plat lantai

$: 25 / 45$

Plat atap

$: 12 \mathrm{~cm}$

$: 10 \mathrm{~cm}$

- Beban hidup

- Lantai 1-4

$: 250 \mathrm{~kg} / \mathrm{m}^{2}$

- Lantai 5 atau atap

$$
: 100 \mathrm{~kg} / \mathrm{m}^{2}
$$

- Beban mati

- Dinding

$: 250 \mathrm{~kg} / \mathrm{m}^{2}$

- Tambahan (lantai 1-4)

$: 120 \mathrm{~kg} / \mathrm{m}^{2}$

- Tambahan (lantai 5 atau atap) $\quad: 100 \mathrm{~kg} / \mathrm{m}^{2}$

Data yang digunakan untuk analisis struktur dengan beban gempa adalah sebagai berikut :

- Pembebanan dinamis dengan prosedur analisis spektrum respons ragam. Pembebanan diterapkan dalam dua arah ortogonal yaitu $100 \%$ gaya untuk satu arah ditambah $30 \%$ gaya untuk arah tegak lurusnya.

- Lokasi bangunan terletak di jalan arteri Soekarno-Hatta Semarang dengan klasifikasi tanah lunak.

Model bangunan yang diteliti adalah gedung dengan denah bangunan berbentuk $T$ dan $L$. Untuk masing-masing bentuk bangunan massa bangunannya dimodelkan secara tersebar dan terpusat, seperti pada Gambar 2 sampai 5. 

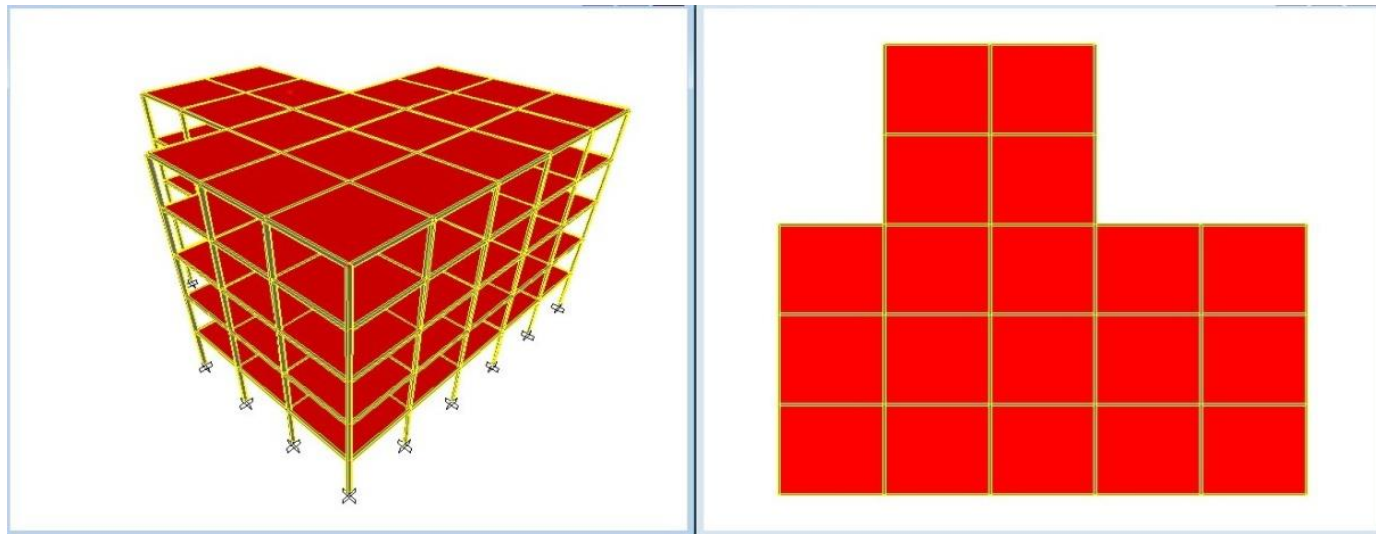

Gambar 2. Model 1a - Denah Berbentuk T dengan Massa Tersebar

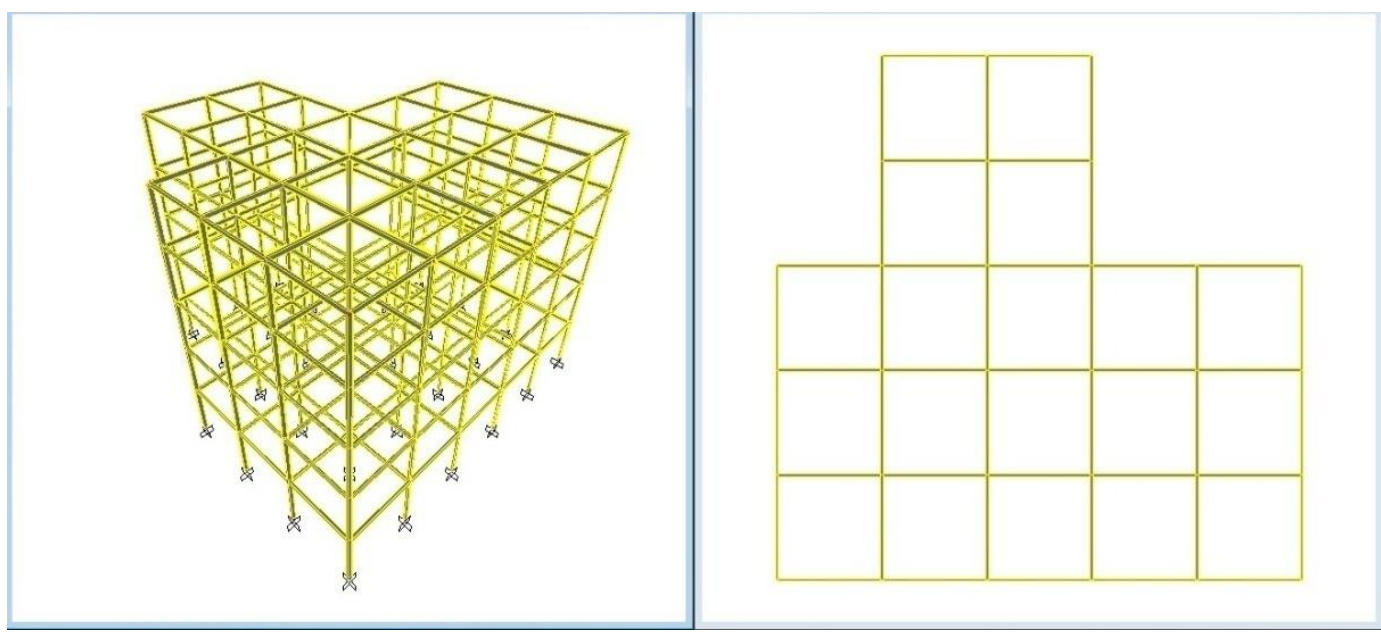

Gambar 3. Model 1b - Denah Berbentuk T dengan Massa Terpusat
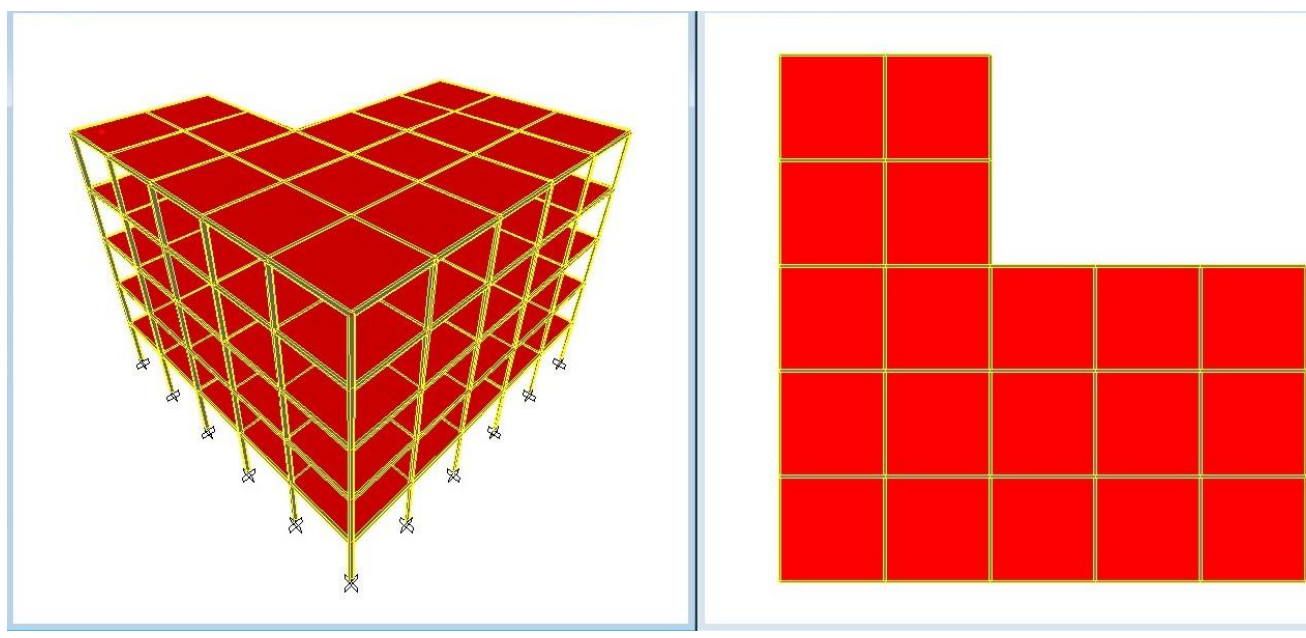

Gambar 4. Model 2a - Denah Berbentuk L dengan Massa Tersebar 

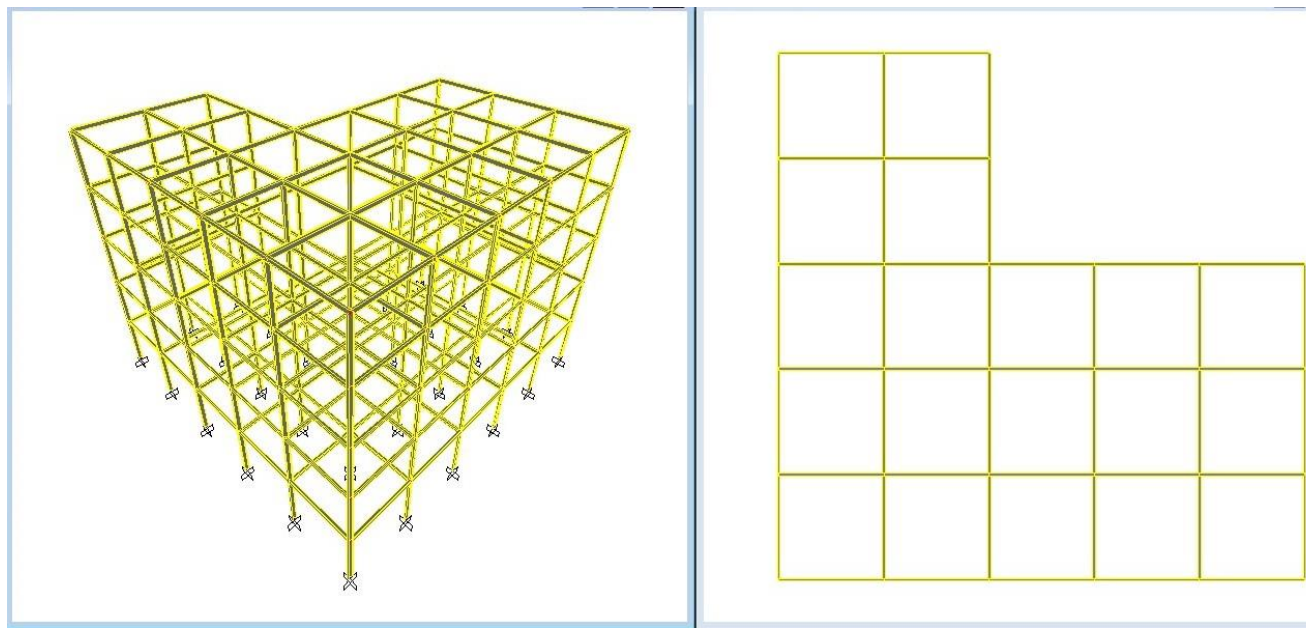

Gambar 5. Model 2b - Denah Berbentuk L dengan Massa Terpusat

\section{HASIL DAN PEMBAHASAN}

\section{Pembuatan Spektrum Respons}

Untuk pembuatan kurva spektrum respons desain elastik pada lokasi penelitian data-data yang dibutuhkan sebagai berikut :

$$
\begin{aligned}
& \mathrm{S}_{\mathrm{s}}=1,024 \mathrm{~g} \\
& \mathrm{~S}_{1}=0,34 \mathrm{~g} \\
& \mathrm{~F}_{\mathrm{a}}=0,9 \\
& \mathrm{~F}_{\mathrm{v}}=2,627 \\
& \mathrm{~S}_{\mathrm{ms}}=\mathrm{F}_{\mathrm{a}}{ }^{*} \mathrm{~S}_{\mathrm{S}}=0,922 \mathrm{~g} \\
& \mathrm{~S}_{\mathrm{m} 1}=\mathrm{F}_{\mathrm{v}}{ }^{*} \mathrm{~S}_{1}=0,902 \mathrm{~g} \\
& \mathrm{~S}_{\mathrm{DS}}=2 / 3^{*} \mathrm{~S}_{\mathrm{Ms}}=0,615 \mathrm{~g} \\
& \mathrm{~S}_{\mathrm{D} 1}=2 / 3^{*} \mathrm{~S}_{\mathrm{M} 1}=0,601 \mathrm{~g} \\
& \mathrm{~T}_{0}=0,2^{*} \mathrm{~S}_{\mathrm{D} 1} / \mathrm{S}_{\mathrm{DS}}=0,196 \text { detik } \\
& \mathrm{T}_{\mathrm{S}}=\mathrm{S}_{\mathrm{D} 1} / \mathrm{S}_{\mathrm{DS}} \quad=0,978 \text { detik }
\end{aligned}
$$

Untuk periode $<T_{0}$ spektrum respons percepatan desain $S_{a}=S_{D S}\left(0,4+0,6^{*} T / T_{0}\right)$

Untuk periode $\geq T_{0}$ dan $\leq T_{S}$ spektrum respons percepatan desain $S_{a}=S_{D S}$

Untuk periode $>T_{S}$ spektrum respons percepatan desain $S_{a}=S_{D 1} / T$

Selanjutnya kurva spektrum respons desain elastik dapat dibuat seperti Gambar 6 di bawah ini :

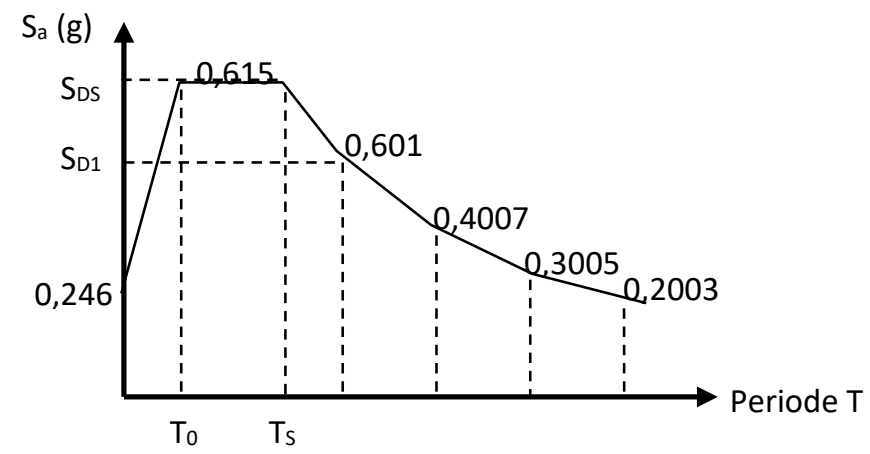

Gambar 6. Pembuatan Kurva Spektrum Respons Desain Elastik Sumber : Peneliti, 2019 


\section{Kategori Desain Seismik}

Gedung yang diteliti jenis pemanfaatannya sebagai gedung perkantoran sehingga termasuk kategori resiko II dengan $I_{e}=1$. Berdasarkan nilai $S_{D S}$ dengan kategori resiko II maka struktur termasuk kategori desain seismik (KDS) D, sedangkan berdasarkan nilai $S_{D 1}$ dengan kategori resiko II maka struktur termasuk KDS D. Sehingga struktur gedung yang diteliti termasuk KDS D.

Material yang dipakai adalah beton bertulang dan sistem penahan gaya gempa yang diijinkan adalah sistem rangka beton bertulang pemikul momen khusus (SRPMK) dengan koefisien modifikasi respons $(R)=8$.

Nilai spektrum respons yang telah dihitung dibagi dengan faktor sebesar $\left(R / I_{e}\right)=(8 / 1)=$ 8. Karena nilai $S_{a}$ pada kurva spektrum respons dinyatakan dalam percepatan gravitasi bumi (g) maka selanjutnya ditambah faktor pengali sebesar $\mathrm{g}=9,81 \mathrm{~m} /$ detik $^{2}$.

\section{Hasil Analisis Struktur}

Model 1a adalah struktur dengan denah bangunan berbentuk $\mathrm{T}$ yang dianalisis dengan massa tersebar, model $1 \mathrm{~b}$ adalah bangunan dengan bentuk yang sama tetapi massa dimodelkan terpusat. Sedangkan model $2 a$ adalah struktur dengan denah bangunan berbentuk $L$ yang dianalisis dengan massa tersebar dan model $2 \mathrm{~b}$ adalah bangunan dengan bentuk yang sama tetapi massa dimodelkan terpusat. Dari hasil analisis struktur dengan SAP 2000 diperoleh hasil seperti pada tabel 1-4.

Tabel 1. Perbandingan Simpangan Maksimum Denah T Arah X (cm)

\begin{tabular}{|c|c|c|}
\hline Lantai & Massa Tersebar & Massa Terpusat \\
\hline 5 & 5,19 & 7,29 \\
\hline 4 & 4,74 & 6,63 \\
\hline 3 & 3,76 & 5,38 \\
\hline 2 & 2,62 & 3,62 \\
\hline 1 & 1,22 & 1,28 \\
\hline
\end{tabular}

Tabel 2. Perbandingan Simpangan Maksimum Denah T Arah Y (cm)

\begin{tabular}{|c|c|c|}
\hline Lantai & Massa Tersebar & Massa Terpusat \\
\hline 5 & 25,25 & 36,86 \\
\hline 4 & 23,67 & 34,99 \\
\hline 3 & 19,94 & 29,63 \\
\hline 2 & 14,42 & 21,33 \\
\hline 1 & 7,52 & 10,98 \\
\hline
\end{tabular}

Tabel 3. Perbandingan Simpangan Maksimum Denah L Arah X (cm)

\begin{tabular}{|c|c|c|}
\hline Lantai & Massa Tersebar & Massa Terpusat \\
\hline 5 & 5,23 & 6,29 \\
\hline 4 & 4,76 & 5,25 \\
\hline 3 & 3,90 & 4,67 \\
\hline 2 & 2,68 & 3,45 \\
\hline 1 & 1,22 & 2,13 \\
\hline
\end{tabular}

Tabel 4. Perbandingan Simpangan Maksimum Denah L Arah Y (cm)

\begin{tabular}{|c|c|c|}
\hline Lantai & Massa Tersebar & Massa Terpusat \\
\hline 5 & 25,23 & 35,65 \\
\hline 4 & 23,61 & 30,76 \\
\hline 3 & 19,89 & 26,88 \\
\hline 2 & 14,42 & 21,42 \\
\hline 1 & 7,54 & 9,54 \\
\hline
\end{tabular}


Dari hasil analisis dapat dilihat bahwa nilai simpangan maksimum untuk model massa terpusat lebih besar dari model massa tersebar pada kedua arah sumbu utama bangunan, baik untuk bangunan dengan denah berbentuk T maupun $\mathrm{L}$.

\section{KESIMPULAN}

Berdasarkan hasil analisis struktur pada bangunan dengan denah $T$ dan $L$ dengan model massa yang berbeda maka dapat ditarik kesimpulan sebagai berikut :

a. Nilai simpangan maksimum untuk pemodelan massa terpusat lebih besar dibandingkan dengan massa tersebar sehingga pemodelan massa terpusat akan memberikan nilai yang lebih konservatif.

b. Simpangan yang lebih besar akan menghasilkan gaya dalam momen lentur yang lebih besar pada elemen kolom, sehingga akan didapat jumlah penulangan yang lebih banyak.

\section{DAFTAR PUSTAKA}

Badan Standarisasi Nasional. (2012). Tata Cara Perencanaan Tahan Gempa untuk Bangunan Gedung dan Non Gedung SNI 1726:2012, Badan Standarisasi Nasional, Jakarta.

Badan Standarisasi Nasional. (2013). Beban Minimum Untuk Perancangan Bangunan Gedung dan Struktur Lain SNI 1727:2013, Badan Standarisasi Nasional, Jakarta.

Chopra, A.K., (2012). Dynamics of Structures, Theory and Application to Earthquake Engineering, Prentice Hall, USA.

Dewobroto, W., (2004). Aplikasi Rekayasa Konstruksi dengan SAP2000, Elex Media Komputindo, Jakarta.

Imran, I. dan Hendrik, F. (2016). Perencanaan Lanjut Struktur Beton Bertulang, ITB Press, Bandung.

Komarudin, R., dan Heri, K. (2017). Analisis Pemodelan Bentuk Gedung T dan L dengan Inertia yang Sama Terhadap Respons Spektrum, Jurnal, Jakarta.

Pranata, Y.A. (2006). Evaluasi Kinerja Gedung Beton Bertulang Tahan Gempa dengan Pushover Analysis, Jurnal, Bandung.

Satryano, I. dan Nawangalam, P. (2012). Belajar SAP2000 Cepat-Tepat-Mahir Seri 2 (Analisis Gempa), Zamil Publishing, Yogyakarta.

Widodo. (2001). Respons Dinamik Struktur Elastik, UII Press, Jogjakarta. 